\title{
Mathematical Simulation and program of gas-liquid two-phase well flow pattern
}

\author{
Quanhua Huang ${ }^{1}$, Xingyu Lin ${ }^{1 *}$, Yunjun $\mathrm{He}^{2}$, Chengyin Wang ${ }^{3}$, Yi Hü ${ }^{4}$, Hongjun Ding ${ }^{1}$, Jian Jiang ${ }^{1}$, Jian Li ${ }^{1}$ \\ ${ }^{1}$ Petroleum engineering school, Southwest petroleum university, Chengdu, Sichuan, 610500, china \\ ${ }^{2}$ Natural gas laboratory, Daqing oilfield exploration and development research institute, Daqing, Heilongjiang, 16300, china \\ ${ }^{3}$ East China Petroleum Bureau, Sinopec, Nanjing, Jiangshu, 210019, China \\ ${ }^{4}$ Central China Branch, China Petrochemical Sales Co.LTD. Wuhan, Hubei, 430021, China
}

\begin{abstract}
The judgment of flow pattern in the wellbore of a liquid-producing gas well is very important to the judgment of its liquid-carrying capacity in the production process. Through mathematical fitting of dunsROS flow pattern of vertical well, Gould flow pattern of inclined well and Goiver flow pattern of horizontal well, the different flow pattern is fitted into 3, 4 and 4 curves respectively, and divided into 9, 10 and 20 regions respectively. The division standard among different regions is given, optimized parameters are selected, and a VB software is edited. The results show that the software fitting effect is accurate, and can be well applied to the actual flow pattern judgment.
\end{abstract}

\section{Introduce:}

How to judge two phase well flow pattern? In the field production, plot method ${ }^{[1-6]}$ is a good choice. In vertical wells, Duns ROS flow pattern diagram, Hewitt Roberts flow pattern diagram, Aziz flow pattern diagram and Gould flow pattern diagram are often used. Gould flow pattern diagram is often used in inclined shaft. Goiver flow pattern diagram and Mandhane flow pattern diagram are often used in horizontal wells. There are also relevant studies in China.

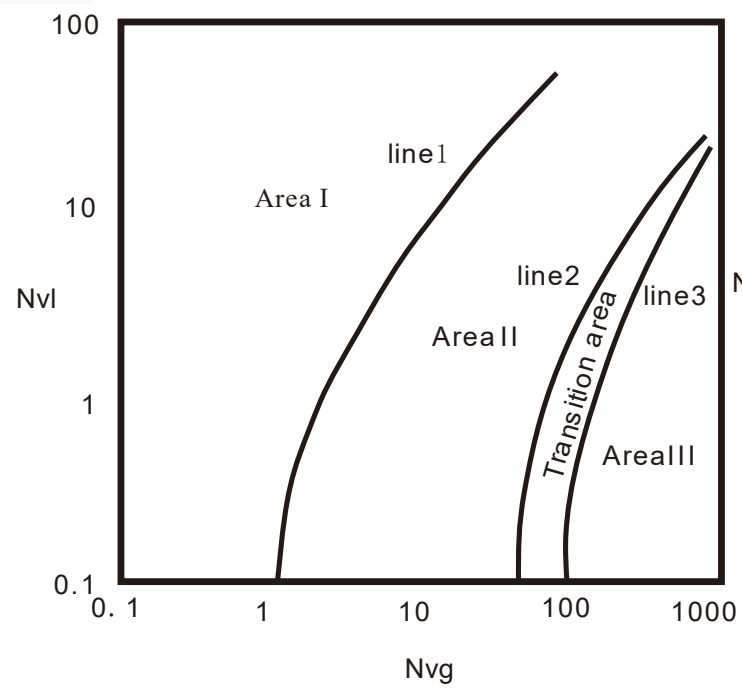

Fig1 Duns-ros flow pattern figure

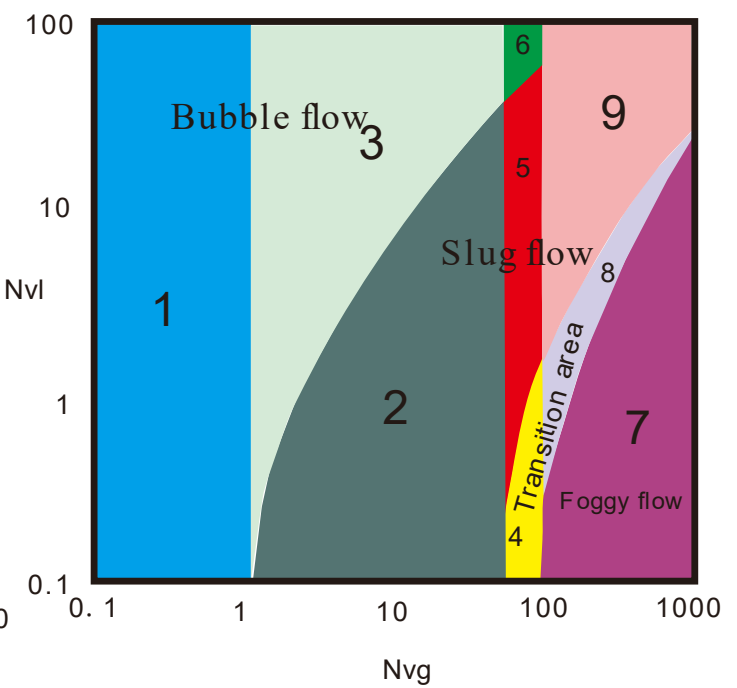

Line1: $y_{1}=-0.0021 x^{2}+0.8406 x-0.8494$

$y_{2}=-8 \times 10^{-9} x^{3}+6 \times 10^{-6} x^{2}+0.0311 x-1.6118$

Line2:

*Corresponding authors e-mail: 364520856@qq.com 
Line3: $y_{3}=-10^{-8} x^{3}+3 \times 10^{-5} x^{2}+0.0094 x-1.0799$

Table1 Area division schematic table
\begin{tabular}{|c|c|c|c|c|c|}
\hline Area & $\mathrm{x}$ & $\mathrm{y}$ & Area & $\mathrm{x}$ & $\mathrm{y}$ \\
\hline 1 & $0 \sim 1.1147$ & $\sim$ & 6 & $\begin{array}{c}53.2617 \\
\sim 100\end{array}$ & $\begin{array}{c}y_{1} \\
\sim\end{array}$ \\
\hline 2 & $\begin{array}{c}1.147 \sim 53.26 \\
17\end{array}$ & $0 \sim y_{1}$ & 7 & $100 \sim$ & $\begin{array}{c}0 \sim \\
y_{3}\end{array}$ \\
\hline 3 & $\begin{array}{c}1.147 \sim 53.26 \\
17\end{array}$ & $y_{1} \sim$ & 8 & $100 \sim$ & $\begin{array}{c}y_{3} \\
y_{2}\end{array}$ \\
\hline
\end{tabular}

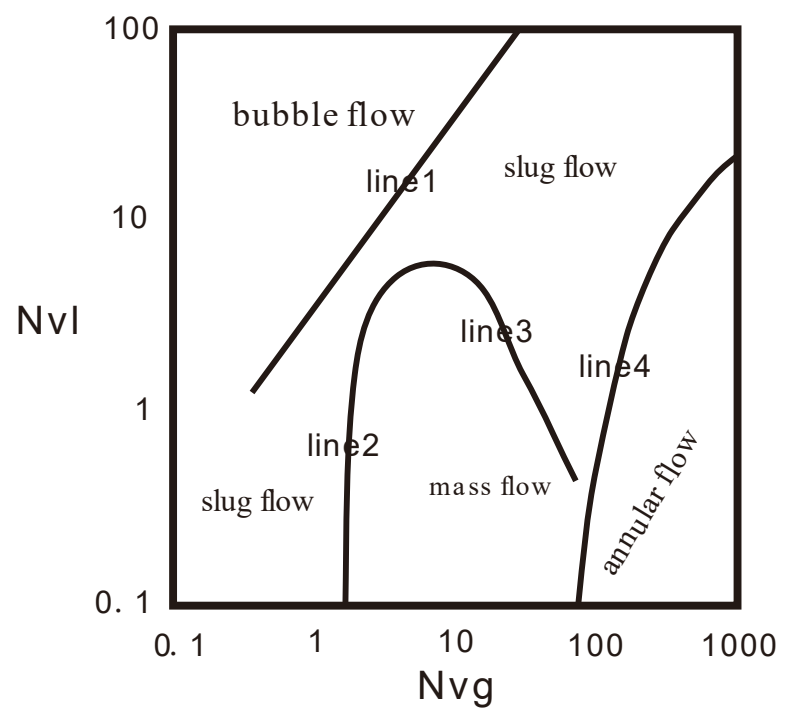

Fig2 Gould flow pattern figure

Line1: $y_{1}=3.5381 x+0.0223$

Line2:

$y_{2}=6 \times 10^{-16} x^{6}-2 \times 10^{-12} x^{5}+2 \times 10^{-9} x^{4}-10^{-6} x^{3}+0.0004 x^{2}-0.0224 x+0.0534$

Line3:

$y_{3}=8 \times 10^{-7} x^{4}-0.0002 x^{3}+0.0173 x^{2}-0.6955 x+11.492$

Line4:

$y_{4}=-0.0005 x^{6}+0.0191 x^{5}-0.2955 x^{4}+2.3739 x^{3}-10.578 x^{2}+25.56 x-21.639$

Table2 Area division schematic table

\begin{tabular}{|c|c|c|c|c|c|}
\hline Area & $\mathrm{x}$ & $\mathrm{y}$ & Area & $\mathrm{x}$ & $\mathrm{y}$ \\
\hline 1 & $0 \sim 1.5959$ & $\begin{array}{c}0 \sim \\
y_{1}\end{array}$ & 6 & $10.717 \sim 69.5193$ & $\begin{array}{c}0 \sim \\
y_{3}\end{array}$ \\
\hline 2 & $0 \sim 1.5959$ & $\begin{array}{c}y_{1} \\
\sim\end{array}$ & 7 & $10.717 \sim 69.5193$ & $\begin{array}{c}y_{3} \sim \\
y_{1}\end{array}$ \\
\hline
\end{tabular}

\begin{tabular}{|c|c|c|c|c|c|}
\hline 4 & $\begin{array}{c}53.2617 \sim 10 \\
0\end{array}$ & $0 \sim y_{2}$ & 9 & $100 \sim$ & $\begin{array}{c}y_{2} \\
\sim\end{array}$ \\
\hline 5 & $\begin{array}{c}53.2617 \sim 10 \\
0\end{array}$ & $\begin{array}{c}y_{2} \sim \\
y_{1}\end{array}$ & & & \\
\hline
\end{tabular}

Gould et al. Carried out the air water two-phase flow experiment in an inclined upward pipe with an inclination angle of $45^{\circ}$ and a diameter of $25 \mathrm{~mm}$ in 1972. The flow pattern diagram of the corresponding pipe inclination was drawn by taking the dimensionless velocity quasi velocity of gas and liquid as the horizontal and vertical coordinates. The flow patterns of the inclined pipe were divided into bubble flow, mass flow, slug flow and annular flow, as shown in Fig. 2.

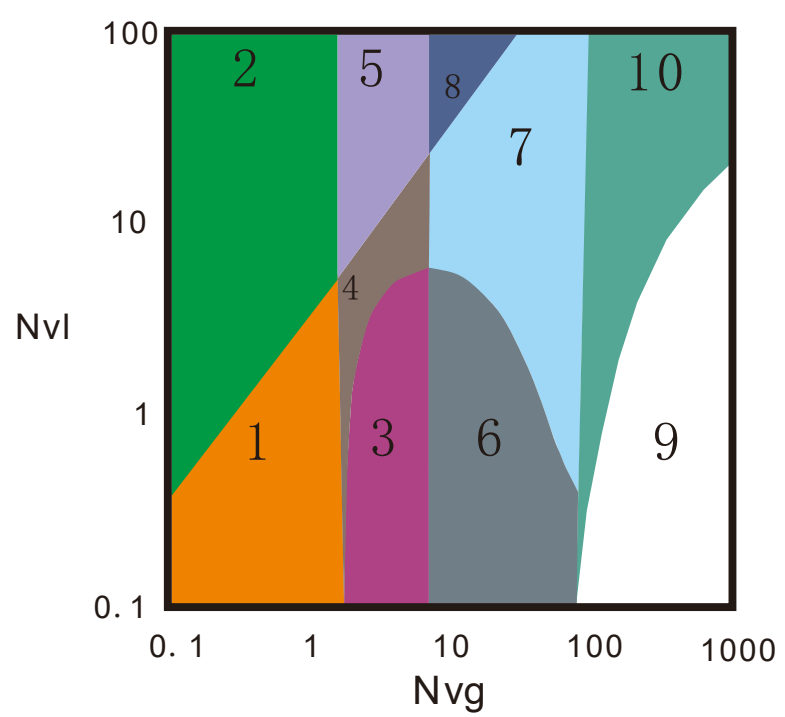

\begin{tabular}{|c|c|c|c|c|c|}
\hline 3 & $1.5959 \sim 10.717$ & $\begin{array}{c}0 \sim \\
y_{2}\end{array}$ & 8 & $10.717 \sim 69.5193$ & $y_{1} \sim$ \\
\hline 4 & $1.5959 \sim 10.717$ & $\begin{array}{c}y_{2} \\
\sim\end{array}$ & 9 & $69.5193 \sim$ & $\begin{array}{c}0 \sim \\
y_{4}\end{array}$ \\
\hline 5 & $1.5959 \sim 10.717$ & $\begin{array}{c}y_{1} \\
\sim\end{array}$ & 10 & $69.5193 \sim$ & $y_{4} \sim$ \\
\hline
\end{tabular}

The classical Goiver model is adopted for the horizontal pipe section, and the flow patterns are divided into six flow patterns: dispersed bubble flow, gas column flow, layered smooth flow, Churn flow, layered wavy flow and annular fog flow, as shown in FIG. 3. 

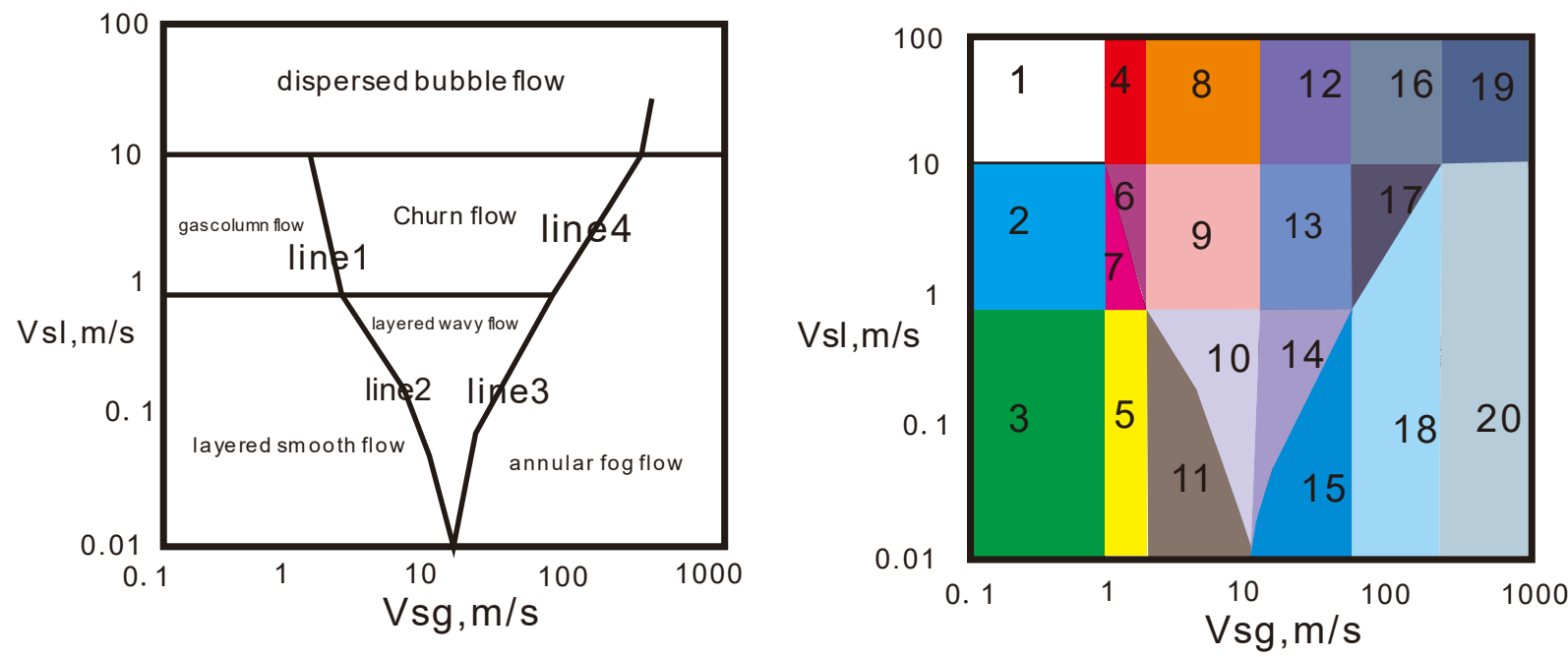

Line1:

Fig3 Goiver flow pattern figure

$$
\begin{aligned}
& y_{1}=27.752 x^{4}-532.87 x^{3}+1213.8 x^{2}-1233.2 x+474.34 \\
& y_{2}=4 \times 10^{-5} x^{6}-0.0018 x^{5}+0.0303 x^{4}-0.2645 x^{3}+1.2738 x^{2}-3.2894 x+3.8247
\end{aligned}
$$

Line3: $y_{3}=0.0002 x^{2}+0.0087 x-0.0984$

Line4: $y_{4}=0.0002 x^{2}-0.0031 x+0.4333$

Table3 Area division schematic table

\begin{tabular}{|c|c|c|c|c|c|}
\hline Area & $\mathrm{x}$ & $\mathrm{y}$ & $\mathrm{Area}$ & $\mathrm{x}$ & $\mathrm{y}$ \\
\hline 1 & $0 \sim 1$ & $10 \sim$ & 11 & $1.7541 \sim 10.5$ & $0 \sim y_{2}$ \\
\hline 2 & $0 \sim 1$ & $0.8 \sim 10$ & 12 & $10.5 \sim 53.7059$ & $10 \sim$ \\
\hline 3 & $0 \sim 1$ & $0 \sim 0.8$ & 13 & $10.5 \sim 53.7059$ & $0.8 \sim 10$ \\
\hline 4 & $1 \sim 1.7541$ & $10 \sim$ & 14 & $10.5 \sim 53.7059$ & $\begin{array}{c}y_{3} \\
\sim 0.8\end{array}$ \\
\hline 5 & $1 \sim 1.7541$ & $\begin{array}{c}y_{1} \\
10\end{array}$ & 15 & $10.5 \sim 53.7059$ & \begin{tabular}{c}
$0 \sim y_{3}$ \\
\hline 6
\end{tabular} \\
\hline $1 \sim 1.7541$ & $\begin{array}{c}0.8 \sim \\
y_{1}\end{array}$ & 16 & $53.7059 \sim 220.5$ & $10 \sim$ \\
\hline 7 & $1 \sim 1.7541$ & $0 \sim 0.8$ & 17 & $53.7059 \sim 220.5$ & $\begin{array}{c}y_{4} \\
\sim 10\end{array}$ \\
\hline 8 & $1.7541 \sim 10.5$ & $10 \sim$ & 18 & $53.7059 \sim 220.5$ & $0 \sim 10$ \\
\hline 9 & $1.7541 \sim 10.5$ & $0.8 \sim 10$ & 19 & $220.5 \sim$ & $10 \sim$ \\
\hline 10 & $1.7541 \sim 10.5$ & $\begin{array}{c}y_{2} \\
\sim 0.8\end{array}$ & 20 & $220.5 \sim$ & $0 \sim 10$ \\
\hline
\end{tabular}

\section{Parameter determination:}

Tubing area: $A=3.14 \times\left(\frac{0.001 d}{2}\right)^{2}$

Apparent velocity of gas phase: $v_{s g}=q_{g} / \mathrm{A}$

Apparent velocity of liquid phase: $v_{s l}=\left(q_{o}+q_{w}\right) / A$

Liquid density: $\rho_{l}=\rho_{o} q_{o}\left(q_{o}+q_{w}\right)+\rho_{w} q_{w}\left(q_{o}+q_{w}\right)$

Gas density: $\rho_{g}=3484.48 \gamma_{g} \frac{P}{T Z}$

The empirical formula is used to calculate the surface tension of gas-liquid:

$$
\sigma_{g w}(p, T)=\frac{1.8(410.93-T)}{206}\left(\sigma_{1}-\sigma_{2}\right)+\sigma_{2}
$$

Where, $\quad \sigma_{1}=76 e^{-0.036257 p} \sigma_{2}=52.5-0.87018 p$

Oil-gas surface tension:

$\sigma_{\text {og }}=[42.4-0.047(1.8 \mathrm{~T}-459.67)-0.267 \mathrm{API}] \exp (-0.10152 \mathrm{p})$

Gas-liquid surface tension:

$\sigma=\left(\sigma_{\mathrm{og}} \frac{q_{o}}{q_{o}+q_{w}}+\sigma_{g w} \frac{q_{w}}{q_{o}+q_{w}}\right) / 1000$

Gas phase velocity criterion: $n_{v g}=v_{s g} \sqrt[4]{\rho_{g} /(9.81 \sigma)}$

Liquid phase velocity criterion:

$n_{v l}=v_{s l} \sqrt[4]{\rho_{l} /(9.81 \sigma)}$

Where, $\sigma —$ Surface tension, N/m; $\sigma_{1}$ surface tension at $23.33^{\circ} \mathrm{C}, \mathrm{N} / \mathrm{m} ; \sigma_{2}$-Water surface tension at $137.78^{\circ} \mathrm{C}, \mathrm{N} / \mathrm{m} ; T-$ The temperature, $\mathrm{K}$; $p$ Pressure, $\mathrm{MPa} ; \mathrm{A}-$ Tubing area, $\mathrm{m}^{2} ; \rho_{g}$ Gas phase density, $\mathrm{kg} / \mathrm{m}^{3} ; \rho_{l}$ _Liquid density, $\mathrm{kg} / \mathrm{m}^{3} ; q_{g}-$ Natural gas production, $m^{3} / \mathrm{s} ; q_{o}$ -Oil production, $m^{3} / \mathrm{s} ; q_{w}$-Formation water production, $m^{3} / \mathrm{s} ; \quad v_{s g} \longrightarrow$ Apparent velocity of gas phase, $\mathrm{m} / \mathrm{s} ; n_{v g} \ldots$ Gas phase velocity criterion; $v_{s l}$

Apparent velocity of liquid phase, $\mathrm{m} / \mathrm{s} ; n_{v l}$ Liquid phase velocity criterion.

\section{Analysis and conclusion:}

By using VB editing a software, input parameters such as daily gas production, daily oil production, daily water production, water density, oil density, gas phase relative density, tubing diameter, pressure and temperature to 
calculate the velocity criterion, and get the flow pattern. The software can also automatically record the results into TEXT files. The example is as follows. Click the calculate button to get the corresponding flow type. At the same time, by comparing the flow pattern results calculated by the software of 50 Wells with those obtained by the chart method, the accuracy is up to $100 \%$, and the predicted results are in good agreement with the chart.

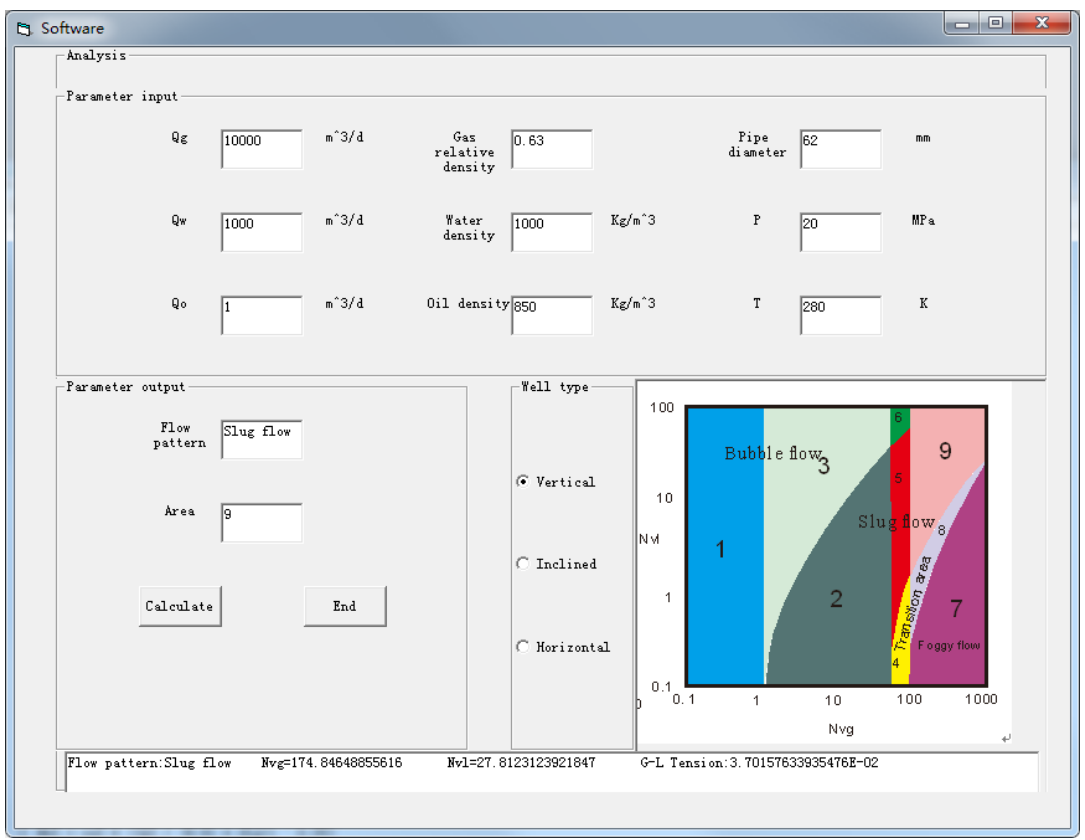

Fig.4 Schematic diagram of software calculation

In this paper, the mathematical equations of three flow patterns are fitted by software, and the corresponding programs are edited. Moreover, the input parameters do not need to be converted, so the calculation effect of the program is good. In the field work, when the experimental conditions are not available to judge the flow pattern. It can greatly reduce the workload of field workers when making flow pattern judgments.

\section{References:}

1. AZIZ, K, GOVIER, G W. (1972) Pressure drop in wells producing oil and gas. Journal of Canadian Petroleum Technology, 11

(3) : 38-47.

2. DIAZ, M, NYDAL, O J. (2015) Inlet effects on flow regimes in downwards inclined pipes. Paper OTC-
26121- MS presented at the OTC Brasil.

3. Mandhane, JM, Gregory, K G.A. Aziz. (1974)A flow pattern map for gas-liquid flow in horizontal pipes. International Journal of Multiphase Flow.

4. GOVIER, G W, AZIZ, K. (1972) The flow of complex mixtures in pipes. New York: Van Nostrand Reinhold Company.

5. Orkiszewski, J. (1967) Prediction Two-phase Pressure Drops in Vertical Pipe. J Pet Tech, (6) :829838.

6. Liu, Y H, Luo, C C, Liu, T, Ren, G T, Wang, Z W. (2019) Prediction of gas-liquid two-phase flow pattern in horizontal gas wells. JOURNAL OF SOUTHWEST PETROLEUM UNIVERSITY (NATURAL SCIENCE EDITION), 41 (03): 107-112 